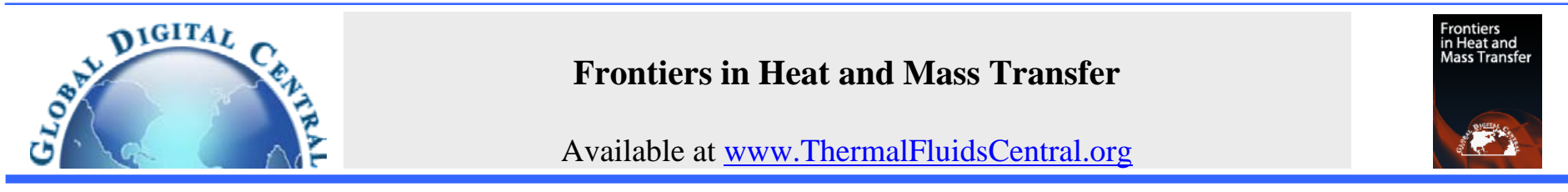

\title{
SATURATED AND SUBCOOLED POOL BOILING OF HFE-7200 MIXTURES ON A COPPER NANOWIRE SURFACE
}

\author{
Aravind Sathyanarayana ${ }^{\mathrm{a}}$, Pramod Warrier ${ }^{\mathrm{b}}$, Yogendra Joshi ${ }^{\mathrm{a}^{*}}$, Amyn Teja ${ }^{\mathrm{b}}$ \\ ${ }^{a}$ G.W.Woodruff School of Mechanical Engineering, Georgia Institute of Technology, Atlanta, GA, 30332, USA \\ ${ }^{b}$ School of Chemical \& Biomolecular Engineering, Georgia Institute of Technology, Atlanta, GA, 30332, USA
}

\begin{abstract}
Electrical and chemical compatibility requirements of electronic components pose significant constraints on the choice of liquid coolants. Dielectric coolants such as Novec fluids and fluoroinerts are plagued by poor thermal properties. This necessitates the development of new heat transfer fluids. In this study we examine mixture formulations that provide an avenue for enhancing the properties of existing heat transfer fluids. Mixture formulations of Novec fluid (HFE 7200) with Methanol and Ethoxybutane are considered. Pool boiling experiments are performed on a copper nanowire surface. The results show an improvement of 24\% and 11\% in the CHF of HFE 7200 - Methanol and HFE 7200 - Ethoxybutane mixtures respectively, when compared to pure HFE 7200 at saturation condition. The mixtures also showed an enhancement in the CHF at subcooled conditions.

Keywords: Pool Boiling, Copper Nanowires, Heat Transfer Enhancement, Mixture
\end{abstract}

\section{INTRODUCTION}

Advances in semiconductor chips have lead to significant thermal management challenges. Increasing heat fluxes are a direct result of an increase in transistor density, processing speeds, and more sophisticated functions being performed. Present day microelectronic systems generate heat fluxes in excess of $100 \mathrm{~W} / \mathrm{cm}^{2}$ for a single chip, 25 $\mathrm{W} / \mathrm{cm}^{2}$ for a multichip module, and $10 \mathrm{~W} / \mathrm{cm}^{2}$ for a printed circuit board (Incropera, 1999). Electronic devices of the future are likely to generate heat fluxes of over $1 \mathrm{~kW} / \mathrm{cm}^{2}$. Thermal management is widely regarded as a key bottleneck in further development of such systems (Tummala et al., 2008).

Air cooling of electronics has been prevalent for a long time due to low cost, ease of maintenance, and high reliability (Incropera, 1999). However, to handle heat fluxes of over $1 \mathrm{~kW} / \mathrm{cm}^{2}$, forced convection of liquids and/or phase change heat transfer will be necessary. Removing heat directly from chips can be done with direct immersion cooling with no intervening thermal conduction or interfacial resistances which provides a greater uniformity of chip temperature (Simons, 1996). All components in such systems reside in a sealed liquid environment (Tummala, 2001). Physical separation allows the use of water as a liquid coolant in indirect cooling methods. However, for direct liquid cooling, electrical and chemical compatibility of the liquid and electronic components pose significant constraints on coolants. These have led to the use of fluoroinerts such as FC-72, FC-86, FC-77, as well as the Novec fluids HFE-7100 and HFE-7200, mainly because of their chemical stability, low dielectric constants, and suitable boiling temperatures (Mohapatra, 2006). These fluids are plagued by low thermal conductivity (only about twice that of air) and specific heat (about the same as that of air). Also, they suffer from incipience overshoot in pool boiling applications due to low surface tension (Arik and Bar-Cohen, 2002), which delays the Onset of Nucleate Boiling (ONB). Moreover, a number of these chemicals may have significant environmental impact (Arik and Bar-Cohen, 2002). These factors necessitate the development of new heat transfer fluids with improved

*Corresponding author.Email: yogendra.joshi@me.gatech.edu heat transfer properties. The properties of known heat transfer fluids can be augmented for specific applications by adding other miscible liquids. Non-linear dependence on composition for properties of such mixtures offers the potential of yielding formulations with enhanced properties. Pool boiling of mixtures has been studied extensively, as seen in Table 1. Review of pool boiling of mixtures is available in the literature (Celata et al., 1994). Mixture formulations provide an added dimension to the search for new heat transfer fluids. Mixtures of Novec fluids with alcohols and ethers are studied here for their pool boiling characteristics from nano-structured surfaces.

\section{EXPERIMENTAL INVESTIGATION}

Boiling experiments are conducted to examine the heat transfer performance of fluid mixtures at atmospheric conditions. In this study, we consider mixtures of HFE 7200 and Ethoxybutane; and HFE 7200 and Methanol each at $10 \%$ volume/volume (v/v) composition. Pool boiling of these mixtures are done at saturated condition and at $10 \mathrm{~K}$ and 20K subcooling. A flip-chip packaged silicon thermal test chip with 10 x $10 \mathrm{~mm}^{2}$ nano-structured boiling surface developed by Im et al., (2010) is utilized. This is illustrated in Fig. 1.

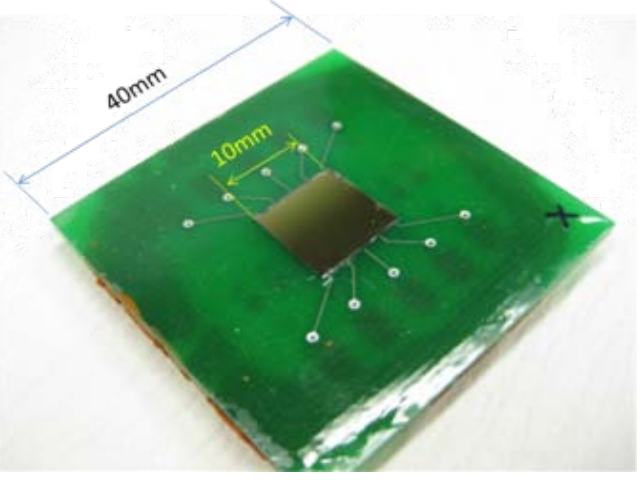

Fig. 1 Test chip 
Table 1 Studies on pool boiling of mixtures

\begin{tabular}{|c|c|c|c|c|}
\hline Author(s)/Year & Mixtures & Surface & Conditions & Observations \\
\hline Van Wijk et al. (1956) & $\begin{array}{l}\text { Water/acetone } \\
\text { water/methylethylketone } \\
\text { water/aliphatic alcohols } \\
\text { water/ethylene glycol }\end{array}$ & $\begin{array}{l}\text { Horizontal platinum wire } \\
(0.02 \mathrm{~cm} \text { diameter, } 6 \mathrm{~cm} \\
\text { length })\end{array}$ & Pressure : $1 \mathrm{~atm}$ & $\begin{array}{l}\text { Maximum value of CHF } \\
\text { occurs at a certain } \\
\text { concentration for all } \\
\text { mixtures. Water/1- } \\
\text { pentanol had the highest } \\
\text { CHF among all the } \\
\text { mixtures }\end{array}$ \\
\hline $\begin{array}{l}\text { Avedisian and } \text { Purdy } \\
\text { (1993) }\end{array}$ & $\begin{array}{l}\text { n-pentane/n-propanol } \\
\text { n-pentane/n-heptane } \\
\text { n-pentane/n-decane }\end{array}$ & $\begin{array}{l}\text { Smooth copper surfaces, } \\
\text { high flux surfaces }\end{array}$ & Pressure : $136-205 \mathrm{kPa}$ & $\begin{array}{l}\text { CHF increases with } \\
\text { increase in the } \\
\text { concentration of more } \\
\text { voaltile liquid (n-pentane). } \\
\text { CHF on high flux surfaces } \\
\text { was higher than that on } \\
\text { smooth Cu surfaces in } \\
\text { pentane/propanol mixture }\end{array}$ \\
\hline Abe et al. (1994) & Water/ethanol & $\begin{array}{l}\text { Indium Oxide film on } \\
\text { pyrex plate }\end{array}$ & $10^{-5} \mathrm{~g}$ condition & $\begin{array}{l}\text { Enhancement of heat } \\
\text { transfer to mixtures by the } \\
\text { reduction in gravity } \\
\text { accompanied by a } \\
\text { fractional reduction in } \\
\text { CHF }\end{array}$ \\
\hline Fujita and Bai (1997) & $\begin{array}{l}\text { Methanol/water } \\
\text { ethanol/water } \\
\text { methanol/ethanol } \\
\text { ethanol/n-butanol } \\
\text { methanol/benzene } \\
\text { benzene/n-heptane } \\
\text { water/ethylene glycol }\end{array}$ & $\begin{array}{l}\text { Horizontal platinum wire } \\
(0.5 \mathrm{~mm} \text { diameter, } 40 \mathrm{~mm} \\
\text { length })\end{array}$ & Pressure : $0.101 \mathrm{MPa}$ & $\begin{array}{l}\text { Mixtures } \\
\text { methanol/water of } \\
\text { ethanol/water showed an } \\
\text { improvement in CHF } \\
\text { whereas mixtures of } \\
\text { methanol/benzene and } \\
\text { water/ethylene glycol had } \\
\text { a reduced CHF }\end{array}$ \\
\hline $\begin{array}{ll}\text { Benjamin } & \text { and } \\
\text { Balakrishnan (1997) } & \end{array}$ & $\begin{array}{l}\text { Acetone/carbon- } \\
\text { tetrachloride } \\
\text { n-Hexane/carbon- } \\
\text { tetrachloride }\end{array}$ & $\begin{array}{l}\begin{array}{l}\text { Aluminum and } \\
\text { steel } \\
\text { surface })\end{array} \\
\begin{array}{l}\text { stainless } \\
\text { circular }\end{array}\end{array}$ & Pressure : 1atm & $\begin{array}{l}\text { Nucleation site density } \\
\text { depends on heater } \\
\text { material, roughness, liquid } \\
\text { properties, vapor-liquid } \\
\text { equilibria and the wall } \\
\text { superheat. Mass transfer } \\
\text { effects significant for large } \\
\text { roughness values }\end{array}$ \\
\hline $\begin{array}{l}\text { Kandlikar and Alves } \\
\text { (1999) }\end{array}$ & Water/ethylene glycol & $\begin{array}{l}\text { Stainless steel tube } \\
\text { 3.08mm OD, } 2.05 \mathrm{~mm} \mathrm{ID,} \\
\text { 42.4mm length }\end{array}$ & Pressure : 1atm & $\begin{array}{l}\text { Heat transfer coefficient } \\
\text { increases slightly with the } \\
\text { addition of small amount } \\
\text { of ethylene glycol }\end{array}$ \\
\hline $\begin{array}{l}\text { Peyghambarzadeh et al. } \\
\text { (2009) }\end{array}$ & $\begin{array}{l}\text { Water/diethanolamine } \\
\text { water/monoethanolamine }\end{array}$ & $\begin{array}{l}\text { Cylindrical stainless steel } \\
\text { heater }(\mathrm{D}=10.67 \mathrm{~mm}, \mathrm{~L}= \\
99.1 \mathrm{~mm})\end{array}$ & Pressure : 1atm & $\begin{array}{l}\text { Reduction in heat transfer } \\
\text { coefficient of mixtures } \\
\text { when compared to pure } \\
\text { fluid }\end{array}$ \\
\hline $\begin{array}{l}\text { Arik and } \text { Bar-Cohen } \\
(2010)\end{array}$ & FC-72/FC-40 & Polished Si & $\begin{array}{l}\text { Pressure : } 1-3 \mathrm{~atm} \\
\text { Fluid temperature : } 22- \\
45{ }^{\circ} \mathrm{C}\end{array}$ & $\begin{array}{l}\text { CHF increased with } \\
\text { increased subcooling and } \\
\text { elevated pressures }\end{array}$ \\
\hline
\end{tabular}

\subsection{Test Chip Fabrication}

The thermal test chip consists of a Platinum (Pt) resistor on one side, and a copper nanowire array on the other side. A Pt thin film resistance thermometer device (RTD) was selected because of high output (temperature coefficient of $0.00385 \Omega /{ }^{\circ} \mathrm{C}$ ), thermal/chemical durability, excellent linearity, and ease of fabrication. Fig. 2 shows the fabrication steps of the thermal test chip (Im, 2009). A silicon dioxide $\left(\mathrm{SiO}_{2}\right)$ layer of $0.4 \mu \mathrm{m}$ thickness is deposited on a $10 \mathrm{~cm}$ diameter P-type $\mathrm{Si}$ wafer by Plasma Enhanced Chemical Vapor Deposition (PECVD) and it serves as an electrical insulation layer. To fabricate the RTD on $\mathrm{SiO}_{2}$ layer, negative photo resist, NR9-8000 (Futurex) is patterned, and $0.05 \mu \mathrm{m}$ thick Titanium (Ti) and $0.4 \mu \mathrm{m}$ thick Pt are deposited as an adhesion layer and RTD layer respectively, by the electron beam process.

Subsequently, the Ti/Pt layer is patterned by lift off process in photo resist remover, RR-41 (Futurex) for 1 hour at $80^{\circ} \mathrm{C}$. To fabricate Under Bump Metallization (UBM) for solder pads of opposite edge, the same lift off process is performed for $0.05 \mu \mathrm{m}$ thick Ti, $0.4 \mu \mathrm{m}$ thick $\mathrm{Cu}$, and $0.2 \mu \mathrm{m}$ thick $\mathrm{Au}$ layers, which act as adhesion layer, solder wetting layer, and oxidation proof layer respectively. After this, $\mathrm{SiO}_{2}$ of $0.4 \mu \mathrm{m}$ is deposited by PECVD and it acts as an electrical passivation layer. The solder pads are then opened with Reactive Ion Etching (RIE). The total resistance of RTD at $25^{\circ} \mathrm{C}$ is around $52 \Omega$. 

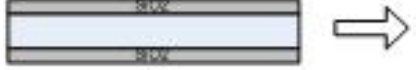

S1O2 CVO (2000A)

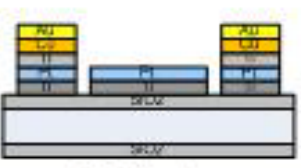

PR patterning

(100A/2000A) Lift OIf
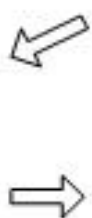

CriAu Eteam Evaporation

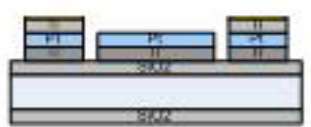

TUPY Ebeam Evaperation $(100 \mathrm{~A}=000 \mathrm{~A})$

Lit ${ }^{\circ}$

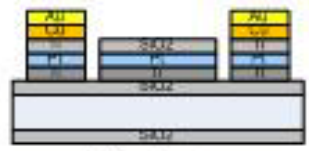

PR potteming

in
PR patheming

Fig. 2 Test chip fabrication process (Im et al., 2010)

\subsection{Fabrication of Copper Nanowires}

An example of nanowires array is shown in Fig. 3. This structure is fabricated by electrochemically assisted template growth of copper as described by Im (2009). Commercial AAO (Anodisc 25, Whatman, 200 $\mathrm{nm}$ pore, $60 \mu \mathrm{m}$ thick, $25 \mathrm{~mm}$ diameter) is used as the template to fabricate nanowires.

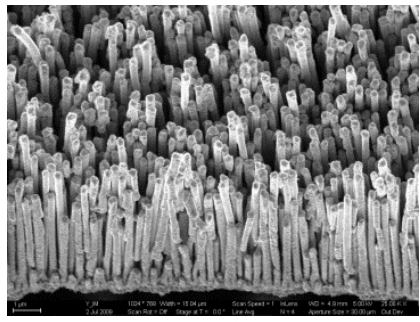

a)

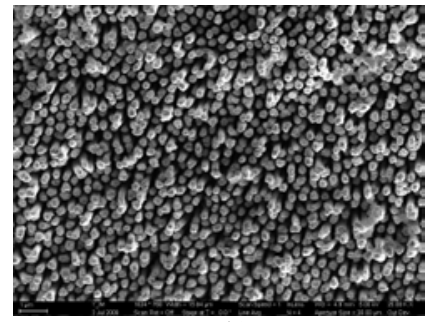

b)
Fig. 3 Copper nanowires on test chip a) side view b) top view

First $\mathrm{Ti}, \mathrm{Cu}$, and $\mathrm{Au}$ films of thicknesses 50, 400, and 200nm respectively were deposited on one side of the AAO template by Ebeam evaporation, to make a seed layer for electrochemical deposition. This AAO was mounted on copper plate using polyimide tape, to give electrical interconnection mechanically and is then immersed in DI water. It is then subjected to sonication for 5 minutes to eject bubbles from electrochemical deposition. Before starting the actual electrochemical deposition, dummy electrochemical deposition was conducted in an electrolytic bath consisting of sulfuric acid $120 \mathrm{ml} / \mathrm{l}$, copper sulfate $90 \mathrm{~g} / \mathrm{l}$, copper carrier $12 \mathrm{ml} / \mathrm{l}$, and copper additive $6 \mathrm{ml} / \mathrm{l}$ for $30 \mathrm{~min}$ to stabilize the electrolyte and the electrode. The electrochemical depositions were conducted at $2.5 \mathrm{~mA}$ DC. The AAO template having copper nanowires was detached from the copper plate after electrochemical deposition. It was then attached to the backside of test chip using Ag epoxy, ablebond 2000T. Finally, free standing copper nanowires were obtained by dissolving the AAO template in 5 wt $\% \mathrm{NaOH}$ solution for $5 \mathrm{~min}$.

\subsection{Packaging}

The test chip is packaged on the printed circuit board (PCB) using flip chip bonding process. To reduce unwanted boiling from the bottom and the edges, the bottom of the chip was filled with underfill material, FP4549 (Henkel). The opposite side of the RTD could be used as the enhanced surface, and there is no boiling from the interconnect lines such as wire bonds. Also, lead free solder with a melting point of $217^{\circ} \mathrm{C}$ is used, as it can withstand the temperatures of the boiling experiment. During the testing process, vacuum conditions were created on the back side of the embedded package to limit heat loss, which was assumed to be negligible.

\subsection{Test Setup}

The schematic of experimental setup closely follows Im (2009) and is shown in Fig. 4. The tests were conducted inside a transparent jacketed beaker. A teflon block having a vacuum chuck at the center was used for mounting the test chip package under vacuum conditions, and two holes were used in the teflon block for passing vacuum hose and electrical wires. The transparent jacketed beaker controls the temperature of the fluid inside and was fitted with the Teflon block and a tight lid using an O-ring and a clamp.

A water cooled condenser coil located in the top portion of the glass chamber is used to condense the vapor. The temperature of the test fluid is monitored using a $0.1 \mathrm{~cm}$ diameter T-type thermocouple dipped in the bath. An additional thermocouple was attached to the bottom of PCB to estimate heat loss. The test chip was powered using an Agilent E3645A power supply and the measured resistance was converted to temperature using the formulated calibration curve. National Instruments Labview software was used to control the power supply and the data acquisition system, and the data obtained were recorded at steady state conditions.

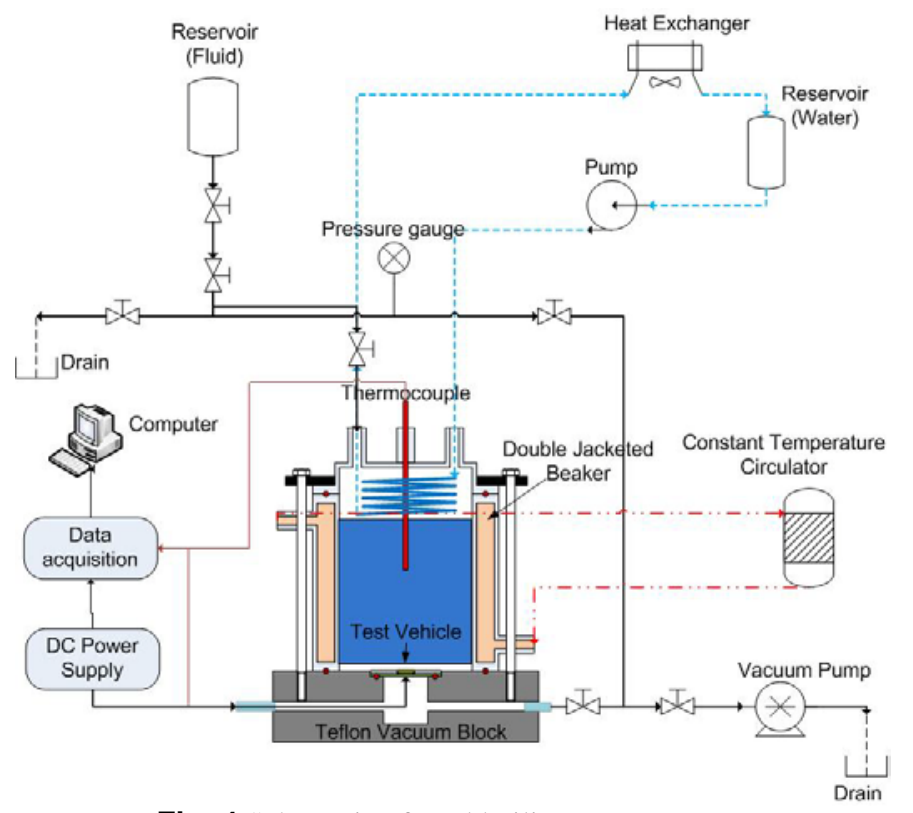

Fig. 4 Schematic of pool boiling setup

\subsection{Test Procedure}

Test chip calibration. The Pt resistor provides simultaneous heating and temperature sensing capabilities. The test chip is placed on a hot plate and shielded from the surroundings by enclosing it in a chamber. The temperature and resistance of the Pt resistor are recorded at each set temperature. The calibration curve is shown in Fig. 5.

Measurement. Pool boiling experiments were performed at saturation condition and at $10 \mathrm{~K}$ and $20 \mathrm{~K}$ subcooling. Prior to the experiment, the fluid was degassed by boiling it vigorously for an hour. To measure the amount of air trapped in the fluid, the fluid was collected after vigorous boiling in a sealed container and the air percentage was measured using Seaton Wilson Aire-ometer. The air percentage for pure HFE 7200, HFE 7200-Methanol and HFE 7200-Ethoxybutane mixtures are 34\%, $31 \%$ and $32 \%$ respectively. After degassing, the experiment was run by supplying power to the test surface. At each power input, data were recorded once the temperature reading of the test surface reached a steady state (temperature variation $<\sim 0.5^{\circ} \mathrm{C}$ ) over a 2 min period. 


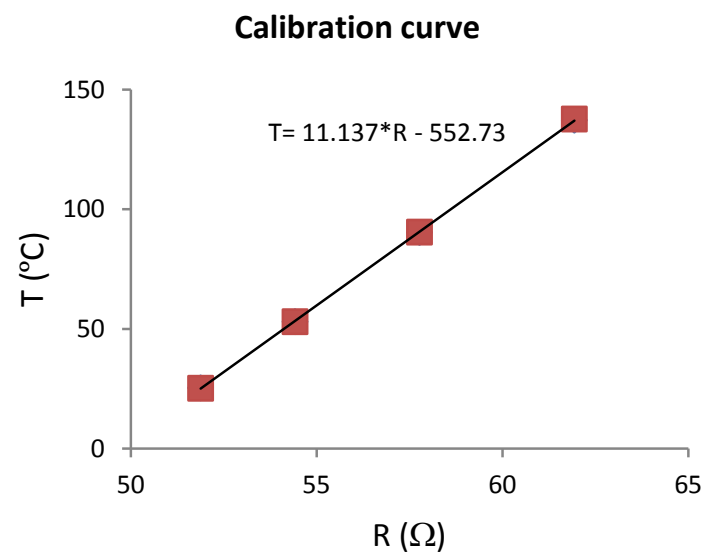

Fig. 5 Calibration curve for Platinum resistor

Since, the actual test conditions are different from the calibrated conditions of the heater, a corresponding offset was input to rectify the error in the calibrated data. To estimate the offset, the temperature value calculated from the resistance is subtracted from the actual temperature measured using the thermocouple immersed in the liquid bath. The same offset is then used for all the temperature readings of the test surface. An average of at least five readings was taken at each power input at steady state for improved accuracy.

The uncertainty in heat flux arises mainly due to the uncertainties in voltage and current of the DC power supply. The uncertainty in the measurement of heat flux following the approach of Kline and McClintock (1953) is given by:

$w_{q^{\prime \prime}}=\sqrt{\left(\frac{\partial q^{\prime \prime}}{\partial V} \cdot w_{V}\right)^{2}+\left(\frac{\partial q^{\prime \prime}}{\partial I} \cdot w_{I}\right)^{2}+\left(\frac{\partial q^{\prime \prime}}{\partial A} \cdot w_{A}\right)^{2}}$

where $q^{\prime \prime}=\frac{V I}{A}$

$\mathrm{w}_{\mathrm{V}}=$ uncertainty in voltage (manufacturer's specifications)

$\mathrm{W}_{\mathrm{I}}=$ uncertainty in current (manufacturer's specifications)

$\mathrm{w}_{\mathrm{A}}=$ uncertainty in area

The uncertainty in the measurement of heat flux is $1.6 \%$. The uncertainty in the measurement of wall temperature results from the uncertainties in the resistance $(\mathrm{R}=\mathrm{V} / \mathrm{I})$ and the temperature-resistance calibration curve. The uncertainty in the wall temperature measurement is $0.81 \%$. The heat transfer coefficient $(\mathrm{h})$ is given by:

$h=\frac{q^{\prime \prime}}{\left(T_{w}-T_{\text {sat }}\right)}$

To prevent the burning of the test chip, its temperature limit is set at $125{ }^{\circ} \mathrm{C}$. When the difference between two successive temperature measurements of the RTD is $\sim 30 \mathrm{~K}$, it is considered that CHF has been reached. The CHF is equal to the power input corresponding to the last observed steady state chip temperature, beyond which this sudden increase in temperature was observed.

\section{PAPER RESULTS AND DISCUSSION}

Boiling curves were generated at 1 atm for different fluids. Ethoxybutane and Methanol were found to be miscible with Novec fluid HFE 7200 . Mixtures of $10 \%$ v/v composition of these fluids with pure HFE 7200 are considered for the present study. Pool boiling experiments were performed using pure HFE 7200, 10 vol\% mixtures of HFE 7200 - Methanol and HFE 7200 - Ethoxybutane.

\subsection{Mixture Properties}

The properties of these mixtures are given in Table 2. Density, thermal conductivity and viscosity were measured using a glass pycnometer (Marsh, 1987), transient hot wire cell method (Bleazard and Teja, 1995) and a Cannon Fenske viscometer (size 25) respectively. Specific heat, heat of vaporization and surface tension were estimated using mass fraction weighted averages. The bubble point and dew point temperatures were estimated using COSMO-RS (Klamt, 2005) software. There is a significant improvement in the thermal properties of these new mixtures by the addition of Methanol/ Ethoxybutane in small quantities to pure HFE 7200.

Table 2 Fluid properties

\begin{tabular}{|l|l|l|l|}
\hline Property & HFE 7200 & $\begin{array}{l}\text { HFE 7200 + } \\
\text { Methanol } \\
(10 \% \mathrm{v} / \mathrm{v})\end{array}$ & $\begin{array}{l}\text { HFE 7200 + } \\
\text { Ethoxybutane } \\
(10 \% \mathrm{v} / \mathrm{v})\end{array}$ \\
\hline $\begin{array}{l}\text { Bubble point } \\
\text { temperature } \\
\left({ }^{\circ} \mathrm{C}\right)\end{array}$ & 76 & 54 & 75 \\
\hline$\rho_{\mathrm{l}}\left(\mathrm{kg} / \mathrm{m}^{3}\right)$ & 1430 & 1393 & 1341 \\
\hline $\mathrm{h}_{\mathrm{fg}}(\mathrm{kJ} / \mathrm{kg})$ & 119 & 447 & 143 \\
\hline $\mathrm{k}(\mathrm{W} / \mathrm{m}-\mathrm{K})$ & 0.07 & 0.11 & 0.08 \\
\hline $\mathrm{C}_{\mathrm{p}}(\mathrm{J} / \mathrm{kg}-\mathrm{K})$ & 1220 & 1293 & 1263 \\
\hline$\sigma(\mathrm{N} / \mathrm{m})$ & 0.014 & 0.016 & 0.014 \\
\hline
\end{tabular}

The vapor liquid equilibrium curve for the mixture of HFE $7200-$ Ethoxybutane and mixture of HFE 7200 - Methanol are shown in Fig. 6. The mixture of HFE 7200 - Ethoxybutane is assumed to be an azeotrope at $10 \% \mathrm{v} / \mathrm{v}$ (molefraction of 0.1 ) and the mixture of HFE 7200 - Methanol is a non-azeotrope at $10 \% \mathrm{v} / \mathrm{v}$ (molefraction of 0.38 ).

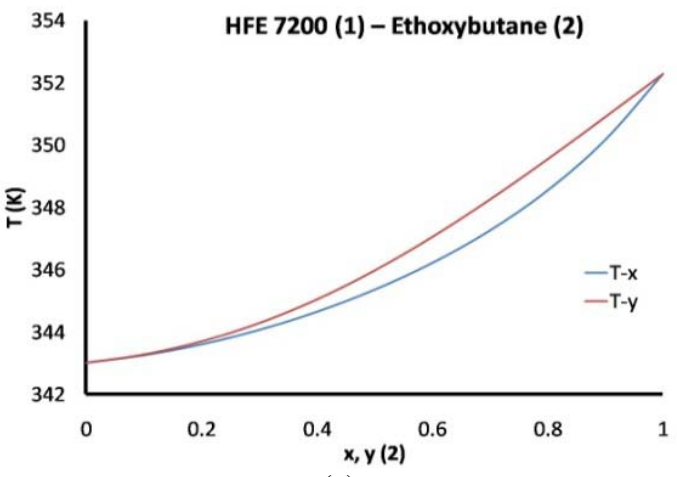

(a)

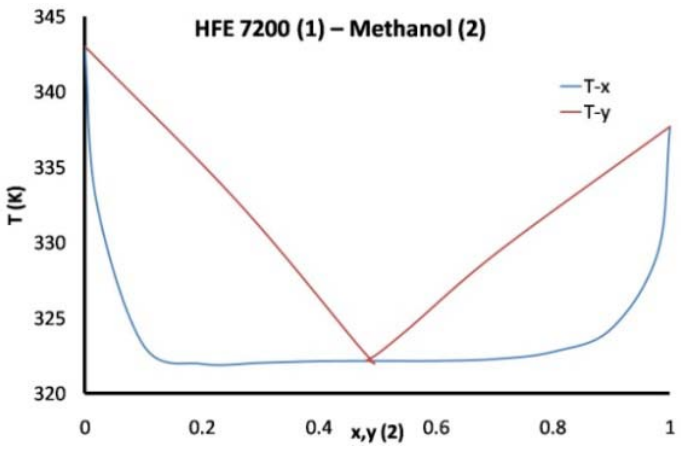

(b)

Fig. 6 Vapor liquid equilibrium curve for a) HFE 7200 - Ethoxybutane mixture b) HFE 7200 - Methanol mixture 


\subsection{Dispensed Droplet Shapes on Chip Surface}

Contact angle plays an important role in boiling heat transfer (Griffith and Wallis, 1960) and it can affect the mechanism of boiling from plain or enhanced surfaces. The instantaneous shape of the dispensed drop of HFE 7200 on bare surface and $4 \mu \mathrm{m}$ nanowire surface are shown in Fig.7. These images were taken at the instant when the drop was dispensed onto the chip surface.

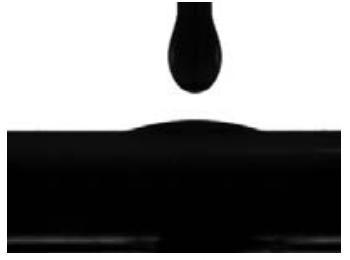

a)

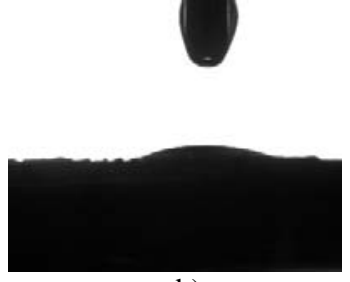

b)
Fig. 7 HFE 7200 droplet on a) bare chip b) $4 \mu m$ nanowire surface

The instantaneous shapes of the dispensed drops of mixtures of HFE 7200 - Methanol and HFE 7200 - Ethoxybutane on $4 \mu \mathrm{m}$ nanowire surface surface are shown in Fig.8. All the three fluids considered in this study are volatile when exposed to the atmosphere making static contact angle measurements impossible.

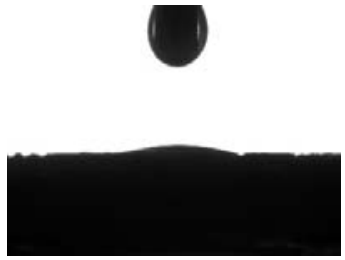

(a)

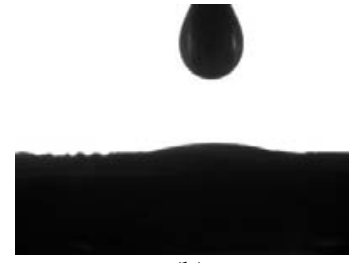

(b)
Fig. 8 Droplet of 10 vol\% mixture of a) HFE 7200 - Ethoxybutane b) HFE 7200 - Methanol, on $4 \mu \mathrm{m}$ nanowire surface

\subsection{Heat Transfer Experiments}

Pool boiling experiments were first performed using HFE 7200 on a bare Silicon (Si) surface and on a Si substrate coated with copper nanowire array.

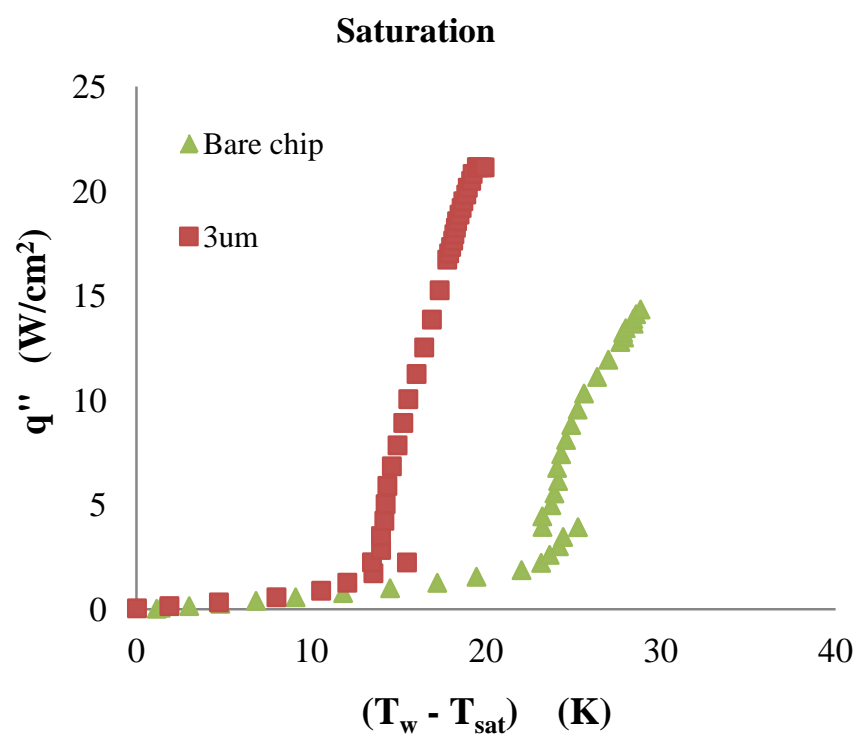

Fig. 9 Effect of nanowire on pool boiling performance
The pitch and the diameter of the nanowire are 200nm each and the height of the nanowire is $3 \mu \mathrm{m}$. The effect of nanowire on pool boiling performance of HFE 7200 at saturation condition is shown in Fig.9. The copper nanowires increase the Critical Heat Flux (CHF) and reduce the wall superheat at ONB, when compared to a bare substrate (Im et al., 2010). Since nanowires have been shown to enhance the heat transfer performance (Im et al., 2010), pool boiling experiments with mixtures were done on a nanowire coated surface. The Scanning Electron Microscope (SEM) image of the Si substrate with copper nanowires is shown in Fig. 3b.

The boiling curves and the heat transfer coefficient curves for the three test fluids at saturation condition, on a substrate with $4 \mu \mathrm{m}$ nanowires are shown in Fig. 10 and Fig.11 respectively. Here, $\mathrm{T}_{\text {sat }}$ refers to the bubble point temperatures of the mixtures in the boiling curve and these temperatures are given in Table 2.

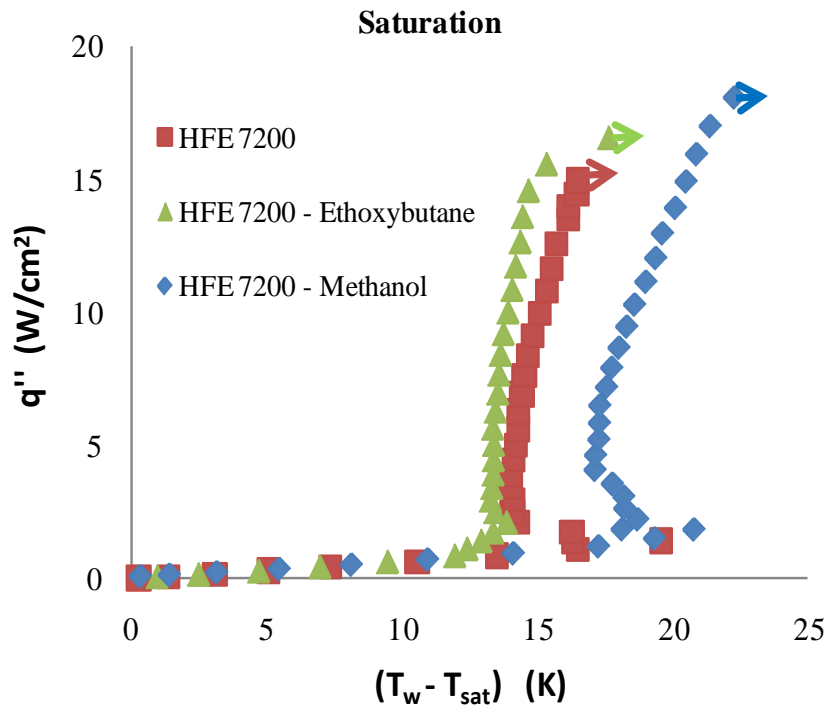

Fig. 10 Pool boiling curves on $4 \mu \mathrm{m}$ nanowires at saturation condition

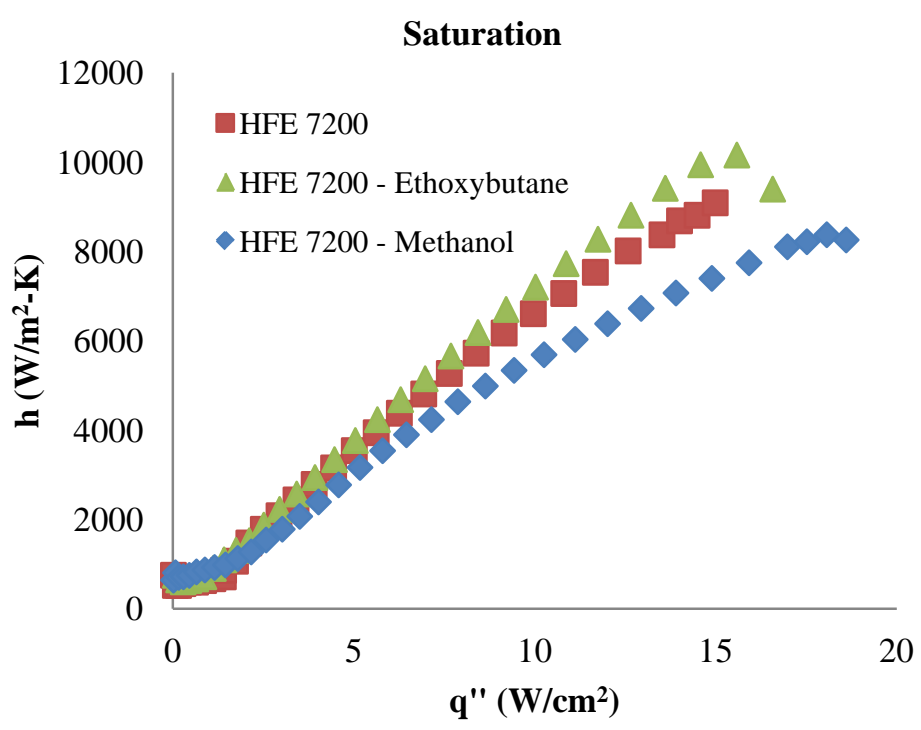

Fig. 11 Heat transfer coefficient curves for pool boiling on $4 \mu \mathrm{m}$ nanowire surface

The boiling curves for the three test fluids at $10 \mathrm{~K}$ and $20 \mathrm{~K}$ subcooling, on a substrate with $4 \mu \mathrm{m}$ nanowires are shown in Fig. 12 and Fig. 13 respectively. The CHF, wall superheat at the ONB for pure HFE 7200, 10 vol\% mixtures of HFE 7200 - Ethoxybutane and HFE 7200 - Methanol are shown in Table 3. 
Table 3 Pool boiling results on $4 \mu \mathrm{m}$ nanowire surface

\begin{tabular}{|l|l|l|l|l|l|l|}
\hline & \multicolumn{2}{|c|}{ Saturation } & \multicolumn{2}{c|}{ 10K Subcooling } & \multicolumn{2}{c|}{ 20K Subcooling } \\
\hline Fluid & CHF (W/cm $\left.{ }^{2}\right)$ & $\begin{array}{l}\text { Wall superheat } \\
(\mathrm{K})\end{array}$ & CHF $\left(\mathrm{W} / \mathrm{cm}^{2}\right)$ & $\begin{array}{l}\text { Wall superheat } \\
(\mathrm{K})\end{array}$ & $\begin{array}{l}\left.\text { CHF (W/cm }{ }^{2}\right) \\
(\mathrm{K})\end{array}$ \\
\hline HFE 7200 & 15 & 19.5 & 19.9 & 30.5 & 28.7 & 37.6 \\
\hline $\begin{array}{l}\text { HFE 7200 - } \\
\text { Ethoxybutane }\end{array}$ & 16.6 & 13.9 & 23.6 & 25 & 31.5 & 34.2 \\
\hline $\begin{array}{l}\text { HFE 7200 - } \\
\text { Methanol }\end{array}$ & 18.6 & 26.8 & 28.2 & 33.5 & 34.5 \\
\hline
\end{tabular}

From Fig.10 and Figs.12-13, it can be observed that the wall superheat for the ONB is lowest for the mixture of HFE $7200-$ Ethoxybutane among the three test fluids, for saturated condition and for $10 \mathrm{~K}$ and $20 \mathrm{~K}$ subcooling. Also, the CHF is highest for the mixture of HFE 7200 - Methanol for saturated and subcooled conditions. The CHF of both the mixtures are higher than that of pure HFE 7200 for all cases. For pool boiling at saturated conditions, the enhancement in CHF for mixtures of

HFE 7200 - Methanol and HFE 7200 - Ethoxybutane over pure HFE 7200 are $24 \%$ and $10.7 \%$.

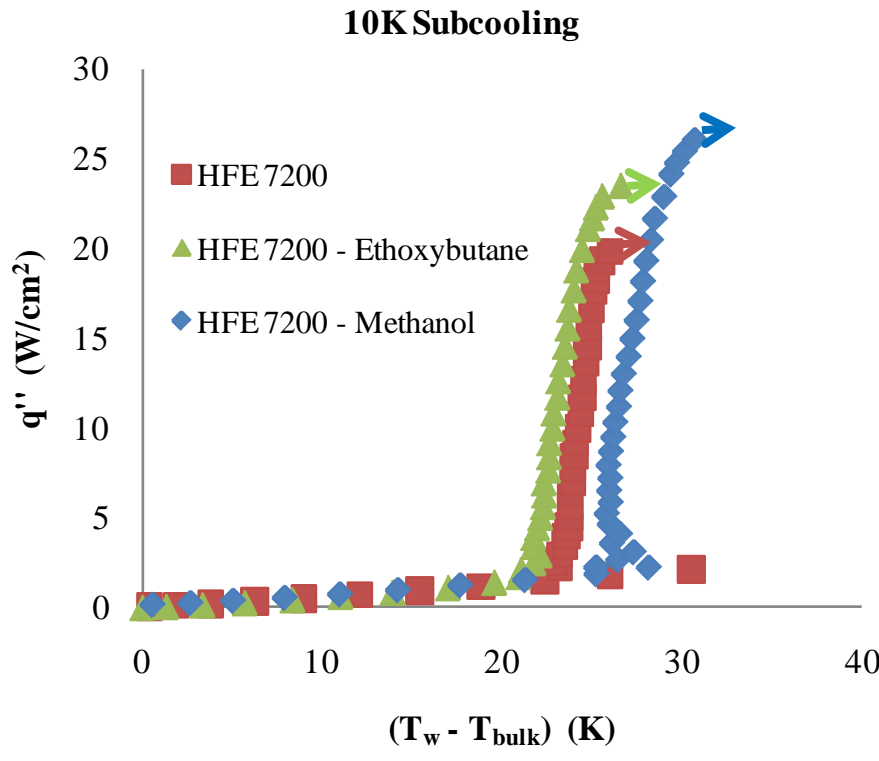

Fig. 12 Pool boiling curves on $4 \mu \mathrm{m}$ nanowires at $10 \mathrm{~K}$ subcooling

For pool boiling at $10 \mathrm{~K}$ subcooled condition, the enhancement in CHF for mixtures of HFE 7200 - Methanol and HFE 7200 Ethoxybutane over pure HFE 7200 are $34.2 \%$ and 18.6\%. For pool boiling at $20 \mathrm{~K}$ subcooled condition, the enhancement in $\mathrm{CHF}$ for mixtures of HFE 7200 - Methanol and HFE 7200 - Ethoxybutane over pure HFE 7200 are $16.7 \%$ and $9.8 \%$. Also, there is no significant change in the boiling curves for these three fluids at 20K subcooling. These results indicate that addition of Methanol and Ethoxybutane to pure HFE 7200 brings about considerable changes in CHF and incipience temperature for pool boiling of these new mixtures.

The boiling points of pure HFE 7200, Ethoxybutane and Methanol are $76{ }^{\circ} \mathrm{C}, 92{ }^{\circ} \mathrm{C}$ and $64.8{ }^{\circ} \mathrm{C}$ respectively. The increase in the CHF of HFE 7200 - Ethoxybutane mixture might be attributed to Marangoni effect. A 10 vol\% mixture of HFE 7200 - Ethoxybutane is a positive mixture (Ahmed and Carey, 1997) wherein the more volatile liquid (HFE 7200) has a lower surface tension than the less volatile liquid (Ethoxybutane). Surface tension gradients arising due to the preferential evaporation of HFE 7200 at the chip surface might act to enhance the flow of liquid from bulk to the surface. This could delay the dryout process and increase the CHF of the HFE 7200 - Ethoxybutane mixture.

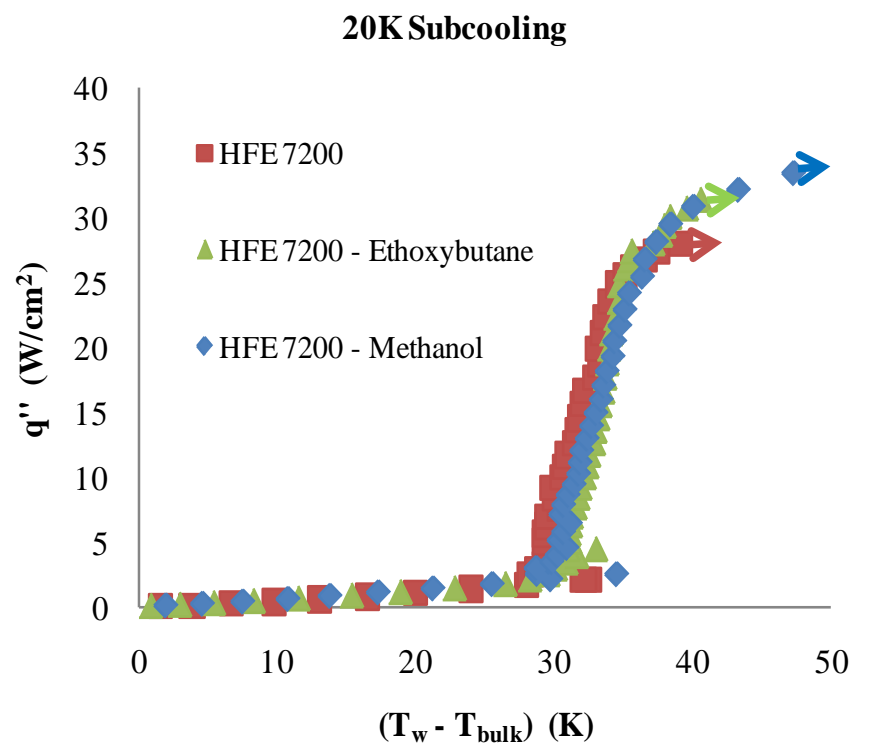

Fig. 13 Pool boiling curves on $4 \mu \mathrm{m}$ nanowires at 20K subcooling

However, the same mechanism cannot account for the increase in CHF of HFE 7200 - Methanol mixture as it is a negative mixture (Ahmed and Carey, 1997), and as such should reduce the CHF. Hence it is clear that there are additional mechanisms which play an important role in the enhancement of CHF for binary mixtures. A significantly large latent heat of evaporation for HFE 7200 - Methanol mixture could play an important role in enhancing the CHF of this negative mixture. High speed visualization might be necessary to observe the boiling phenomena for these fluids and interpret the actual mechanism for enhancement in the CHF.

\section{CONCLUSIONS}

Pool boiling of pure HFE 7200, mixtures of HFE 7200 - Methanol and HFE 7200 - Ethoxybutane are investigated experimentally in this study. Adding Methanol and Ethoxybutane to pure HFE 7200 enhances the thermal properties of the resulting mixtures. Mixture of HFE 7200 and Methanol had the highest CHF among the three fluids at saturated as well as different subcooled conditions. Also mixture of HFE 7200 and Ethoxybutane had the lowest incipience temperature for boiling at saturated as well as different subcooled conditions. Hence, addition of Methanol and Ethoxybutane to pure HFE 7200 brings out significant improvement in the boiling performance of these new mixtures.

\section{ACKNOWLEDGEMENTS}

The authors acknowledge the financial support from the Office of Naval Research (ONR) under contract N000140811057 P00002 monitored by Dr. Mark Spector. The authors would like to thank Yunhyeok Im for designing the pool boiling experimental setup. They acknowledge the use of Aire-ometer in the laboratory of Professor Sushil Bhavnani at Auburn University. 


\section{NOMENCLATURE}

$\begin{array}{ll}A & \text { test chip area }\left(\mathrm{m}^{2}\right) \\ c_{p} & \text { specific heat }(\mathrm{J} / \mathrm{kg} \cdot \mathrm{K}) \\ h & \text { heat transfer coefficient }\left(\mathrm{W} / \mathrm{m}^{2}-\mathrm{K}\right) \\ h_{f g} & \text { latent heat of vaporization }(\mathrm{J} / \mathrm{kg}) \\ \mathrm{I} & \text { current }(\mathrm{A}) \\ k & \text { thermal conductivity }(\mathrm{W} / \mathrm{m} \cdot \mathrm{K}) \\ q^{\prime \prime} & \text { heat flux }\left(\mathrm{W} / \mathrm{m}^{2}\right) \\ \mathrm{R} & \text { resistance }(\Omega) \\ T & \text { temperature }(\mathrm{K}) \\ \mathrm{V} & \text { voltage }(\mathrm{V}) \\ \mathrm{w} & \text { uncertainty }\end{array}$

Greek Symbols

$$
\begin{array}{ll}
\rho & \text { density }\left(\mathrm{kg} / \mathrm{m}^{3}\right) \\
\sigma & \text { surface tension }(\mathrm{N} / \mathrm{m})
\end{array}
$$

\section{Subscripts}

w wall

sat saturation

\section{REFERENCES}

Abe, Y., Oka, T, Mori, Y., and Nagashima, A., 1994, "Pool Boiling of non-Azeotropic Binary Mixture under Microgravity”, International Journal of Heat and Mass Transfer, 37 (16), 2405 - 2413. http://dx.doi.org/10.1016/0017-9310(94)90282-8

Ahmed, S., and Carey, V.P., 1997, "Effect of Gravity on the Boiling of Binary Fluid Mixtures”, International Journal of Heat and Mass Transfer, 41 (16), 2469 - 2483.

http://dx.doi.org/10.1016/S0017-9310(97)00334-7

Arik, M., and Bar-Cohen, A., 2002, Ebullient Cooling of Integrated Circuits by Novec Fluids, Technical Report GRC027, GE Global Research

Arik, M., and Bar-Cohen, A., 2010, "Pool Boiling of Perfluorocarbon Mixtures on Silicon Surfaces”, International Journal of Heat and Mass Transfer, 53, 5596 - 5604.

http://dx.doi.org/10.1016/j.ijheatmasstransfer.2010.06.034

Avedisian, C.T., Purdy, D.J., 1993, "Experimental Study of Pool Boiling Critical Heat Flux of Binary Fluid Mixtures on an Infinitive Horizontal Surface”, Advances in Electronic Packaging, 4-2, 909-915.

Benjamin, R.J., and Balakrishnan, A.R., 1997, "Nucleation Site Density in Pool Boiling of Binary mixtures: Effect of Surface Micro-roughness and Surface and Liquid Physical Properties", The Canadian Journal of Chemical Engineering, 75, 1080 - 1089.

http://dx.doi.org/10.1002/cjce.5450750611

Bleazard, J.G., and Teja, A., 1995, "Thermal conductivity of electrically conducting liquids by the transient hot-wire method", Journal of Chemical \& Engineering Data, 40, 732-737. http://dx.doi.org/10.1021/je00020a003

Celata, G.P., Cumo, M., and Setaro, T., 1994, "A Review of Pool and Forced Convective Boiling of Binary Mixtures”, Experimental Thermal and Fluid Science, 9, 367 - 381. http://dx.doi.org/10.1016/0894-1777(94)90015-9

Fujita, Y., and Bai, Q., 1997, "Critical Heat Flux of Binary Mixtures in Pool Boiling and its Correlation in Terms of Marangoni Number”, International Journal of Refrigeration, 20 (8), 616 - 622.

http://dx.doi.org/10.1016/S0140-7007(97)00026-1

Griffith, P., and Wallis, J.D., 1960, "The Role of Surface Conditions in Nucleate Boiling”, Chemical Engineering Progress Symposium Series, AIChE, 56, 49-63.

Im, Y., Joshi, Y., Dietz, C., Lee, S.S., 2010, "Enhanced boiling of a dielectric liquid on copper nanowire surfaces", International Journal of Micro-Nano Scale Transport, 1, 79 - 95.

http://dx.doi.org/10.1260/1759-3093.1.1.79

Im, Y., 2009, "Copper Nanowire and Flower-like CuO Nanostructure Surfaces for Enhanced Boiling," Thesis (PhD), Department of Mechanical Engineering, Korea Advanced Institute of Science and Technology.

Incropera, F.P., 1999, Liquid Cooling of Electronic Devices by SinglePhase Convection, Wiley Interscience.

Kandlikar, S.G., and Alves, L., 1999, "Effects of Surface Tension and Binary Diffusion on Pool Boiling of Dilute Solutions: An Experimental Assessment”, Journal of Heat Transfer, 121 (2), 488 - 493. http://dx.doi.org/10.1115/1.2826008

Klamt, A., 2005, COSMO-RS from quantum chemistry to fluid phase thermodynamics and drug design, The Netherlands: Elsevier

Kline, S. J., and McClintock, F. A., 1953, Describing Uncertainties in Single-Sample Experiments, Mechanical Engineering, 75, 3-8.

Marsh, K.N., 1987, Recommended reference materials for the realization of physicochemical properties, Blackwell Scientific Publications

Mohapatra, S.C., 2006, "An Overview of Liquid Coolants for Electronics Cooling”, Electronics Cooling, 12 (5), 1-6.

Peyghambarzadeh, S.M., et al., 2009, "Experimental and Theoretical Study of Pool Boiling Heat Transfer to Amine Solutions”, Brazilian Journal of Chemical Engineering, 26, 33 - 43. http://dx.doi.org/10.1590/S0104-66322009000100004

Simons, R.E., 1996, "Direct Liquid Immersion Cooling for High Power Density Microelectronics”, Electronics Cooling, 2(2), 1-6.

Tummala, R.R., and Swaminathan, M., 2008, Introduction to SystemOn-Package (SOP), McGraw Hill.

Tummala, R.R., 2001, Fundamentals of Microsystems Packaging, McGraw-Hill.

Van Wijk, W.R. et al., 1956, "Heat Transfer to Boiling Binary Liquid Mixtures”, Chemical Engineering Science, 5, 68 - 80. http://dx.doi.org/10.1016/0009-2509(56)80020-1 